\title{
Accessibility, sustainability, excellence: The UK approach to Open Access
}

\author{
Dame Janet Finch \\ University of Manchester, Manchester, UK \\ E-mail: damejanetfinch@aol.com
}

\begin{abstract}
The report of the UK Working Group on Expanding Access to Research Publications was based on the principle that the potential social and economic benefits of high-quality research could be maximized by making the published results freely and rapidly accessible, with minimal limitations on their use. We regarded this principle as compelling and fundamentally unanswerable. It is also widely accepted.

We also recognised that research communications are already in a period of transition towards open access. The aim was to find ways to accelerate that transition, but also to sustain what is valuable in a complex ecology with many different agents and stakeholders, by managing the transition in an orderly way.

Our strong view was and is that the UK should embrace the transition to open access. We do not believe that the status quo is stable, and also not that the process of change could or should be put into reverse. Rather, the Group recommended that we should seek to accelerate the process in a measured way, which promotes innovation but also sustains what is most valuable in the research communications system.
\end{abstract}

Keywords: Open Access, scholarly publishing, transition management

\section{A Working Group on Expanding Access to Research Publications}

The Working Group on Expanding Access made its final report available on 18 June 2012 [1]. The Working Group developed ten recommendations, enabling the United Kingdom to embrace open access and coordinate a transition. On behalf of the government, the Minister for Universities and Science, David Willets, responded on 16 July 2012, accepting and supporting the recommendations [2].

I chaired the Working Group from October 2011 to June 2012. Its members were senior representatives of the key stakeholders in scholarly publishing, namely the universities, libraries, learned societies, publishers and research funders. Prior to chairing the working group, I had not been involved in any of the open access debates. I have been an academic all my life. As a sociologist I stand somewhere in between the sciences and humanities, working in the library as well as leading big empirical projects, publishing books as well as articles. Also, I led a University for fifteen years. My role was to guide the collaborative efforts of the working group in order to achieve consensus, if that were possible. Fortunately, the representatives of all stakeholders on the group were sufficiently senior able to carry their constituencies with them, facilitating the joint development of the major recommendations as well as pointers to implementation.

In what follows, I review the remit, process and outcome of the Working Group in a personal capacity. The Working Group report is easily accessible online in its full version as well as by an executive summary. When necessary and appropriate, I will refer to the report and quote from it. Yet, this account seeks to illuminate not just what was agreed but also how that agreement came about. To date, the UK 
is the only constituency that has managed to agree jointly among all stakeholders a policy direction towards open access while specifying a transition scenario. Hence I hope that this account may be useful to stakeholders in other countries.

\section{Remit of the Working Group}

The Working Group was commissioned by the UK government, but independent in its deliberations. Its members were senior representatives of the key stakeholders in scholarly publishing, namely the universities, libraries, learned societies, publishers and research funders. ${ }^{1}$

The Working Group was charged with developing solutions for widening access to the published outcomes of research, specified as access to more organisations and people for free and immediate access with the ability to re-use the material. Any solution must be designed to sustain the ecosystem as a whole and also be sustainable for each of the key stakeholders. Moreover, any solutions should support the high standards of peer review in scholarly publishing as well as the quality of UK research overall.

\section{From the terms of reference:}

The purpose of the group is to provide a means through which representatives of the HE sector, research funders, the research community, scholarly publishers, libraries and other interested parties can examine how most effectively to expand access to the quality-assured published outputs of research; and to propose a programme of action to that end.

$\cdots$

The working group will be independent of Government, but its activities, findings and recommendations will be considered by Government.

...

The group will adopt an evidence-based approach to its work. So far as possible it will work collaboratively and will seek to achieve consensus. Where that is not possible, it will seek to identify precise points of difference.

We were not asked to debate whether open access was a good thing or not - it was taken for granted. The Working Group was charged with finding the best possible way of realizing this aim without damaging the scholarly communications system, including its main features in the United Kingdom. The main potential pitfalls which we identified were: damaging the high quality of research in the United Kingdom, the standards of peer review, the commercial publishing industry or learned societies in their role as publishers.

We were asked to deliberate on the published outcome of research, but decided to focus mainly on journal articles and conference proceedings. The reason for this is that monographs still are not published electronically to the same degree. That said, the Working Group was aware that in the future monographs must be brought into the open access world. Hence, while disciplinary variations in publishing were recognized, the Working Group nevertheless worked on the assumption that all must embrace expanded access - even if the means whereby and the speed of transition may vary.

\footnotetext{
${ }^{1}$ Quick Link to terms of reference and meeting minutes of the Working Group via the website of the Research Information Network - http://www.researchinfonet.org/publish/finch/wg/.
} 


\section{The drivers for change}

Deliberations were premised on recognizing, embracing and managing the change towards a new, wider access regime to the scholarly literature. Central to the drive for expanding access is the moral and political case that public funding of research should lead to free and ready access for all to the outcomes of research. Moreover, transparency with regard to the outcomes - i.e. publications, reports and data is inherently desirable, serving the progress of scholarship and, potentially, its acceleration.

It is important to recognize that the UK government is very serious about transparency, and that there is a wider political agenda to make public data and information transparent and available for re-use. Hence, the political agenda encompasses more than just research.

In scholarly publishing, the new digital era resulted in large-scale infrastructure investments into the licensing regime, particularly by publishers and libraries, resulting in easy access to large amounts of content, enabling researchers to consume and produce more. These changes are reflected in the prices and operating expenses, creating severe cost pressure for libraries.

However, most researchers want online instant access to all research outcomes published worldwide, and they want to be free to use new tools to organize, analyze and manipulate content. One may expect the next wave of innovation to centre on data, semantics and the mining of the scholarly corpus.

Scholars, funders and libraries often advocate that transparency is best accomplished by open access, by which users are free to use, re-use and redistribute without restrictions. The result has been the creation and implementation of open access policies, centring on journals and repositories.

\section{Characteristics of the Working Group}

To my mind, we were genuinely free to pursue independent lines of reasoning in responding to the charge of expanding access. All along, we opted for a transparent process, for example, by quickly making available the minutes of our meeting publicly. Moreover, Working Group members frequently relayed interim discussion results back to their constituencies for feedback. This helped us understand how ideas, suggestions and recommendations were being received. We also concentrated on getting the job done as quickly as possible, assuming that extended deliberations would not increase the likelihood of a successful outcome.

Having senior representatives on board meant that they could speak authoritatively for their constituencies. We accepted that stakeholders had different but equally legitimate interests. We did not assume that these would be easy to reconcile, but rather accepted that the outcome would not be perfect for anyone, but a compromise - hopefully a fair compromise that everybody could live with.

To this end to keep the process moving forward to a consensual outcome, we developed a series of success criteria so as to be able to examine all possible solution for the best fit to these criteria.

\section{Access and business models in scholarly publishing}

There are two main routes of access to scholarly publication, depending on the business model adopted by publishers: subscription-based licensing, and open access publishing. In the subscription model, services to the author are free and the costs of publishing are covered by or on behalf of the reader. Open access publishing means that the costs are borne by or on behalf of the author, with services free to the reader. 
Repositories, which gather together material to make it more readily available to users, may play a role in both models, but they are particularly important under subscription-based publishing.

At present both business models co-exist but there is significant disciplinary variation. Whereas in the UK up to $40 \%$ of journal articles in the life and medical sciences are available in some open access format, in some other disciplines the proportion is much lower. There is also disciplinary variation in the balance between journal articles, refereed conference papers and monographs.

One also needs to understand that the total UK output is only six percent of global scholarly publishing. Any UK policy will not necessarily affect the other $94 \%$, which means that no matter how much or how rapidly UK-based authors convert to open access, it will still be necessary to subscribe to published outcomes emanating from elsewhere.

\section{Working Group success criteria}

With key stakeholders represented in the Working Group, interests conflicted. For example,

- Universities seek to maximize research performance and cost control;

- Researchers seek to publish in the best journals;

- Research funders seek maximum impact and cost control;

- Libraries seek to maximize services to readers and cost control;

- Publishers seek revenues to secure profitability and high quality of their products and services.

In seeking to establish consensual success criteria, the Working Group identified the following:
A. More UK publications freely accessible across the world;
B. More publications from across the world accessible to the higher education and research sectors in the UK;
C. More publications from across the world accessible to other sectors in the UK;
D. Financial sustainability for publishing;
E. Costs and affordability for research funders;
F. Costs and affordability for universities;
G. Sustaining high-quality research;
H. High-quality services to readers.

\section{Adapting the subscription-based model?}

Using these criteria, the Working Group discussed the possibility of extending access on the basis of the subscription model, and considered whether this would meet the criteria. This would require:

- Limiting restrictions on subscription-based access to a minimum;

- Repositories comprehensively archiving pre-publication versions for immediate access;

- Extension of licences to cover more journals and more libraries at the local and national level.

We concluded that no matter how much the subscription-based model is adapted, for the underlying business model to be sustainable, restrictions are required. Principally, these are restrictions in terms of access to the published version (to those who have paid for it) and also restrictions upon repositories (i.e. embargoes after publication) to allow publishers to recoup their costs. Hence, while adaptations to the subscription-based model can help to extend access, this model does not fully meet the success criteria. 


\section{Expanding open access publishing?}

Open access publishing, so-called Gold Open Access, fundamentally changes the access and business model. Costs are covered at a much earlier stage of the process - at the point of publication - removing any need for restrictions.

This means that

- Research funders must accept publication as part of the research costs, also beyond the lifetime of any specific research grant, requiring appropriate policy and payment mechanisms;

- We recommended that this could best be achieved by Universities establishing publication funds, not just from competitive research grants but also from their block-grant funding to pay articleprocessing charges, and they must collaborate in negotiating charges with the publishers;

- Publishers must develop much more open access publications, innovate and be prepared to negotiate article-processing charges.

\section{Best fit to the success criteria}

The Working Group found that open access publishing has the best fit with the success criteria. It makes more publications freely available in the version of record, while offering cost control to funders, universities and libraries as well as keeping professional publishing sustainable. The feasibility of open access publishing has already been demonstrated. About ten percent of the international journal output is already published under this model and growth has been very rapid. Moreover, it has spawned innovation in publishing.

Yet, expanding open access publishing also has it challenges. The funding channels for scholarly publishing would need to be altered, and this is likely to be a gradual process because of the many stakeholders involved (not just type of stakeholders, but sheer number of stakeholders). Additional transition costs will be incurred as the two systems run in parallel.

\section{The main recommendations}

Our main conclusion was that for foreseeable future a mixed economy would exist in journal publishing, whereby the subscription-based and open access publishing would coexist. Overall, however, the policy direction should be set towards open access publishing.

The ten recommendations made by the Working Group are [1]:

(i) a clear policy direction should be set towards support for publication in open access or hybrid journals, funded by APCs, as the main vehicle for the publication of research, especially when it is publicly funded;

(ii) the Research Councils and other public sector bodies funding research in the UK should following the Wellcome Trust's initiative in this area but recognizing the specific natures of different funding streams - establish more effective and flexible arrangements to meet the costs of publishing in open access and hybrid journals;

(iii) support for open access publication should be accompanied by policies to minimise restrictions on the rights of use and re-use, especially for non-commercial purposes, and on the ability to use the latest tools and services to organise and manipulate text and other content; 
(iv) during the period of transition to open access publishing worldwide, in order to maximise access in the HE and health sectors to journals and articles produced by authors in the UK and from across the world that are not accessible on open access terms, funds should be found to extend and rationalise current licences to cover all the institutions in those sectors;

(v) the current discussions on how to implement the proposal for walk-in access to the majority of journals to be provided in public libraries across the UK should be pursued with vigour, along with an effective publicity and marketing campaign;

(vi) representative bodies for key sectors including central and local Government, voluntary organisations, and businesses, should work together with publishers, learned societies, libraries and others with relevant expertise to consider the terms and costs of licences to provide access to a broad range of relevant content for the benefit of consortia of organisations within their sectors; and how such licences might be funded;

(vii) future discussions and negotiations between universities and publishers (including learned societies) on the pricing of big deals and other subscriptions should take into account the financial implications of the shift to publication in open access and hybrid journals, of extensions to licensing, and the resultant changes in revenues provided to publishers;

(viii) universities, funders, publishers, and learned societies should continue to work together to promote further experimentation in open access publishing for scholarly monographs;

(ix) the infrastructure of subject and institutional repositories should be developed so that they play a valuable role complementary to formal publishing, particularly in providing access to research data and to grey literature, and in digital preservation;

(x) funders' limitations on the length of embargo periods, and on any other restrictions on access to content not published on open access terms, should be considered carefully, to avoid undue risk to valuable journals that are not funded in the main by APCs. Rules should be kept under review in the light of the available evidence as to their likely impact on such journals.

The UK government accepted all the recommendations, offered GBP $10 \mathrm{mln}$ to pump prime the transitional costs. The Research Councils UK announced further policy development in line with these recommendations, as did the Higher Education Funding Council for England.

\section{The transitional landscape}

We anticipated that, if the policy direction towards open access publishing would be accepted, then the UK would enter a transitional phase. We regarded it as important that the transition should be carefully managed to avoid destabilising the scholarly publication system. The funders' requirement for open access would increasingly be fulfilled by open access publishing but the interim also by making articles in subscription-based journals freely available after an embargo period, expected to be six months for science, technology, engineering and medicine, and twelve months for all other subjects. Also, UK policy will encompass UK-based authors only, so subscription to worldwide content remains essential. Subscription licences should be extended to cover more academic institutions and interested parties elsewhere. Critical to extended access to subscription-based content is the improved use of repositories.

Variation must also be recognized and accommodated. Some scholarly disciplines will need more time to shift towards open access because they start from much lower levels. Consequently, learned societies, particularly those publishing, should be given time to adapt their business models, if they need to do so. Overall, funders and universities have to adjust their processes for paying article-processing charges. 
The transition has to be managed in a way, which does not compromise the freedom of researchers to publish in the most appropriate journals, nor undermines the quality of research and publications.

For the UK alone, the additional costs for the transition are estimated to be in the order of GBP 50-60 mln, of which GBP $38 \mathrm{mln}$ will fall on the university sector, particularly research-intensive universities. However, major variance may be introduced by the speed with which other major countries move towards open access and open access publishing.

It was fundamental to our recommendations that the costs of publication should be accepted explicitly as part of the costs of research and therefore ultimately be borne by research funders. However we saw Universities, the employers of researchers who undertake most publicly funded research, as the parties who should take responsibility for the payment of article-processing charges (APCs). It was therefore necessary to devise a mechanism for Universities to perform this role in a flexible way, and the creation of publication funds was our preferred solution.

Within this overall approach there are two linked elements: (i) identifying funds to be used to pay APCs (ii) distributing those funds. Universities have a key role in both elements, but the creation and operation of publication funds is new territory for them. It is right that they should now be working with research funders and other relevant parties to develop the practical details of how this system will work. It is also to be expected that this will take some time to become embedded in University processes.

\section{Conclusions}

Some of the responses to our Report have been framed as if our sole focus was on support for a rapid move towards 'Gold' open access; that is, the model where the costs of publishing journal articles shifts from readers to authors in the form of Article Processing Charges (APCs). In fact our key conclusion was that, for the foreseeable future, no single mechanism alone could meet the success criteria that we defined as:

- Increasing accessibility and usability for publications both from UK and overseas authors;

- Sustaining high-quality publishing and dissemination services for both authors and readers; and

- Financial sustainability for publishing but also for HE and research funders.

We envisaged a mixed economy, in which measures to expand access would include support for publication in Gold open access journals, extensions to licensing, and the further development of repositories. Within that context, we did indeed recommend that "a clear policy direction should be set towards support for publication in open access or hybrid journals, funded by APCs", and that the Research Councils and others should establish more effective and flexible funding arrangements to that end.

Thus we presented what we believe is a balanced package of recommendations which involve compromises and trade-offs on the part of each of the key groups of stakeholders in the research communications system, whilst offering a clear longer term vision. We stressed the importance of not taking any single measure in isolation, not least because effective progress depends on continuing co-operation and goodwill between all the parties.

I have no further role in the implementation of the new policies but I have agreed to chair a review of progress against our recommendations after twelve month, in the summer of 2013, so for the moment I am keeping an open mind on this. 


\section{Working Group members}

Dame Janet Finch, DBE (Chair)

Professor of Sociology, University of Manchester

Simon Bell

Head of Strategic Partnerships and Licensing, British Library

Dr Laura Bellingan, FSB

Head of Science Policy, Society of Biology

Robert Campbell

Senior Publisher, Wiley Blackwell

Professor Peter Donnelly, FRS

Professor of Statistical Science, University of Oxford and Director of the Wellcome Trust Centre for Human Genetics

Dr Rita Gardner, CBE

Director, Royal Geographical Society

Professor Martin Hall

Vice Chancellor, University of Salford and Chair, Open Access Implementation Group

Steven Hall

Managing Director, IoP Publishing

Robert Kiley

Head of Digital Services, Wellcome Trust

Wim van der Stelt

Executive Vice President Corporate Strategy, Springer

David Sweeney

Director, Research Innovation and Skills, HEFCE

Phil Sykes

Librarian, University of Liverpool and Chair, Research Libraries UK

Professor Adam Tickell

Pro-Vice-Chancellor (Research and Knowledge Transfer), University of Birmingham

Drs Astrid Wissenburg

Partnerships \& Communication and Deputy CEO, ESRC, and chair of the RCUK Knowledge Transfer and Economic Impact Group

Ron Egginton, OBE (Observer)

Research Base Directorate, Department for Business Innovation and Skills

Dr Michael Jubb (Secretary)

Director, Research Information Network

\section{References}

[1] Report of the Working Group on Expanding Access to Published Research Findings, Accessibility, sustainability, excellence: how to expand access to research publications, June 2012, available at: http://www.researchinfonet.org/wpcontent/uploads/2012/06/Finch-Group-report-FINAL-VERSION.pdf.

[2] Department for Business Innovation \& Skills of the UK Government, Letter to Dame Janet Finch on the Government Response to the Finch Group Report: "Accessibility, sustainability, excellence: how to expand access to research publications", available at: http://www.bis.gov.uk/assets/biscore/science/docs/1/12-975-letter-government-response-to-finchreport-research-publications.pdf. 